Document downloaded from:

http://hdl.handle.net/10251/102749

This paper must be cited as:

Segura, M.; Maroto, C. (2017). A multiple criteria supplier segmentation using outranking and value function methods. Expert Systems with Applications. 69:87-100.

doi:10.1016/eswa.2016.10.031

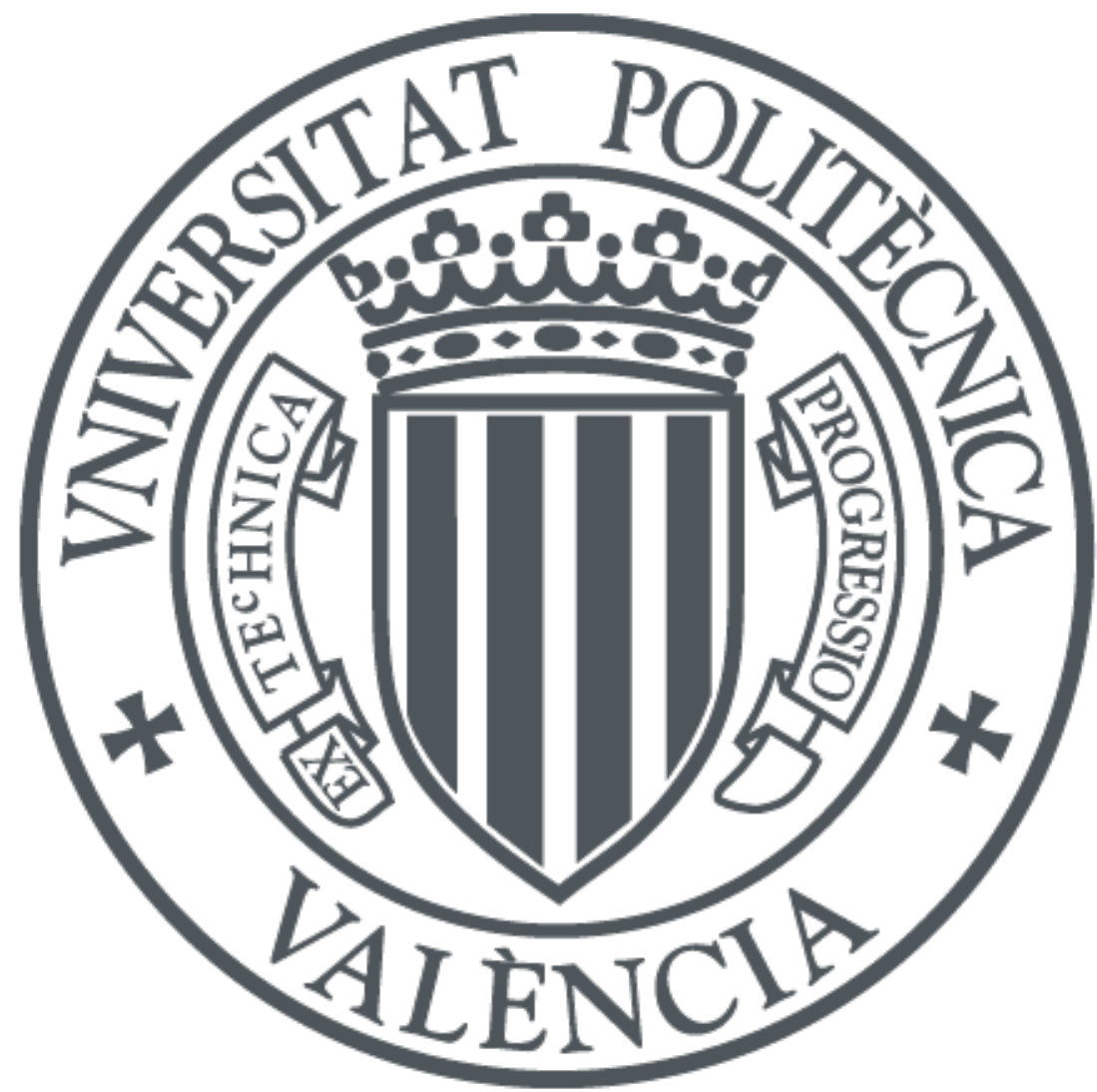

The final publication is available at

https://doi.org/10.1016/j.eswa.2016.10.031

Copyright Elsevier

Additional Information 


\title{
A multiple criteria supplier segmentation using outranking and value function methods
}

\author{
Marina Segura; Concepción Maroto \\ Department of Applied Statistics and Operations Research and Quality. Universitat Politècnica \\ de València. Camino de Vera, s/n 46022 Valencia, Spain.
}

E-mail addresses: masema@upvnet.upv.es; $\underline{\text { cmaroto@eio.upv.es; }}$

Keywords: Supplier evaluation; PROMETHEE; Analytic Hierarchy Process; Multi-Attribute Utility Theory; supplier management; Group Decision Making.

\begin{abstract}
Suppliers play a key role in supply chain management which involves evaluation for supplier selection problem, as well as other complex issues that companies should take into account. The purpose of this research is to develop and test an integrated system, which allows qualifying providers and also supplier segmentation by monitoring their performance based on a multiple criteria tool for systematic decision making. This proposal consists in a general procedure to assess suppliers based mainly on exploiting all reliable databases of the company. Firstly, for each group of products, their evaluation criteria are defined collaboratively in order to determine their critical and strategic performance, which are then integrated with other criteria that are specific of the suppliers and represent relevant aspects for the company, also classified by critical and strategic dimensions. Two multiple criteria methods, compensatory and noncompensatory, are used and compared so as to point out their strengths, weaknesses and flexibility for the supplier evaluation in different contexts, which are usually relevant in the supply chain management. A value function approach is the appropriate method to qualify providers to be included in the panel of approved suppliers of the company as this process depends only on own features of the supplier. On the other hand, outranking methods such as PROMETHEE have shown greater potential and robustness to develop portfolios with suppliers that should be partners of the company, as well as to identify other types of relationships, such as long term contracts, market policies or to highlight those to be removed from their portfolio. These results and conclusions are based on an empirical research in a multinational company for food, pharmaceuticals and chemicals. This system has shown a great impact as it represents the first supplier segmentation proposal applied to industry, in which decision making not only takes into account opinions and judgements, but also integrates historical data and expert knowledge. This approach provides a robust support system to inform operative, tactical and strategic decisions, which is very relevant when applying an advanced management in practice.
\end{abstract}




\section{Introduction}

Nowadays companies cannot offer a sustainable and quality manufacturing without excellent raw materials. Therefore, qualifying, selecting, segmentation, monitoring and controlling suppliers are key activities of the supply chain management. Working with the best approved providers is not enough as the material and service quality, as well as market risks should be tested and proved over time by using a systematic and robust procedure. Nevertheless, the published research mainly deals with supplier evaluation for selection, which has become the traditional problem of literature about purchasing management. Since suppliers are qualified for each particular product and they usually provide several materials or services, their assessment should take this feature into account.

Rezaei \& Ortt (2012) analysed the evolution of theoretical approaches focused on supplier segmentation, which are classified by these authors in three groups: process, portfolio and involvement methods. The first case is the oldest conceptual approach in which supplier segmentation is identified for each item and based on its main characteristics. From the Kraljic's method (Kraljic, 1983), which is the first portfolio approach based on profit impact and supply risk, the majority of proposals have portfolio and involvement nature, which means that the conceptual and empirical approaches for supplier segmentation are focused on the characteristics of supplied items as well as on the relationships between the company and its suppliers.

Gelderman \& Van Weele (2005) analysed categories of items in depth, based on the Kraljic's matrix, which are noncritical, bottleneck, leverage and strategic items, as well as the recommend best actions for each group. From a survey to Dutch companies these authors concluded that the higher the professionalism of purchasers, the higher the use of portfolio models. They also pointed out that criticism to portfolio models had come from theoretical and conceptual studies, while they are supported by qualitative case studies.

The review from Day et al. (2010) has shown that the approaches to supplier categorization are conceptual or based on survey questionnaires and case studies. One of these latter is from Lee \& Drake (2010), who applied portfolio models by using AHP to obtain weights of criteria, and direct rating to obtain the score of items. Rezaei \& Ortt (2013a) used fuzzy AHP to solve this problem in a medium size company by obtaining data through interviews with purchasers. These authors also applied fuzzy logic for supplier segmentation in the same company obtaining expert knowledge through interviews (Rezaei \& Ortt, 2013b). Recently, Rezaei et al. (2015) used a new method, the Best Worst Method (BWM), in order to obtain criteria weights for supplier development.

From the perspective of quantitative models there are two basic formulations of the supplier selection problem. In the simplest one the company looks for the best supplier who can provide the required quantity of a product. The second type is several suppliers to satisfy the demand when it is necessary. In this case the problem consists of choosing the best suppliers and determining the quantities to buy from each of them (Demirtas \& Üstün, 2008). Nevertheless, procurement issues have different phases and complexity. After the problem formulation and selection of criteria for decision making, it is necessary to qualify new suppliers for each product and evaluate their performance in comparison with other providers in the panel if this is the case. The final step is not choosing the best since the current trend in supply chain management consists of having a panel with few reliable suppliers to develop partnerships. In 
general, the relations between companies and its providers should not be based on punctual assessments and thus systematic re-evaluations are essential, for example monthly, quarterly or annually.

Supplier evaluation problem has a multiple criteria nature as there is a wide number of objectives to be taken into account. Literature reviews point out that the main individual and integrated approaches used to solve this problem are Data Envelopment Analysis (DEA), mathematical programming (linear and integer programming, goal programming and multiobjective programming), Analytic Hierarchy Process (AHP) and Analytic Network Process (ANP). In general DEA is used to rank efficient and inefficient suppliers as in Zeydan et al. (2011), and AHP to obtain the weights of criteria. There are other techniques such as Technique for Order Performance by Similarity to Ideal Solution (TOPSIS), Simple MultiAttribute Rating Technique (SMART), Preference Ranking Organization Method for Enrichment Evaluation (PROMETHEE), Genetic Algorithms (GA), Neural Networks (NN), Particle Swarm Optimization (PSO), etc. (Ho et al., 2010; Chai et al., 2013). An updated analysis of literature on purchasing management also supports that the articles have mainly focused on supplier selection taking into account one product only (Sen et al., 2009, Amid et al., 2011; Chen, 2011; Lin, 2012; Ekici, 2013; Chang et al., 2014, Dweiri et al, 2016).

Fuzzy set theory has been integrated with multiple criteria techniques, as fuzzy PROMETHEE (Chen et al., 2011), fuzzy AHP (Rezaei \& Ortt, 2013a; Kar, 2014). In the last years there has been an increasing number of articles, which include fuzzy numbers based on uncertainty about data. This is true in many contexts, but not always necessary. Factories have databases with historical information from suppliers which have not been used to improve management and should be exploited for systematic decision making. In particular, many companies can implement an advanced system for supplier portfolio management by analysing these available data along with market information.

In addition, the increasing professionalism in purchasing management (Gelderman \& Van Weele, 2005) and the trends in supply chain demand flexible systems to support decision making in complex problems that appear in companies nowadays. To the best of our knowledge there is a lack of studies which deal with the more general problem of evaluating suppliers, who can provide the company with several products and simultaneously the products themselves are delivered by several approved vendors with the goal to establish the most appropriate relationships with them.

The purpose of this paper is to develop a system which allows evaluating suppliers by using multiple criteria methodology and group decision making in order to highlight the appropriate relationship with each supplier according to internal and external information about products and providers. This system integrates all relevant quantitative and qualitative criteria for decision making in purchasing management. Thus, internal characteristics of the production process and markets should be taken into account in order to establish the best relationship between the company and its providers. In addition, the process and tools used must be robust, easy to understand and should integrate different points of view of the departments involved. These features are essential in order to implement the decision making tools for supplier evaluation and to improve supply chain management in practice.

In short, the main contribution of this paper is located in the supplier segmentation phase by applying a multiple criteria approach based on PROMETHEE and Multi-Attribute Utility Theory (MAUT), using AHP for eliciting the weights of criteria. Different to previous 
segmentation proposals which are only based on opinions, judgments and direct rating, we have contributed new strategic and critical dimensions to classify suppliers by analysing historical and reliable indicators needed in a decision support system which allows companies to inform decision making at operative, tactical and strategic levels. In addition, the system, which has been validated in a real company, is a novel and unified approach to deal with qualifying suppliers for each product, followed by selecting the best providers and monitoring for supplier segmentation by systematic evaluation in order to develop the appropriate relationships with them.

The rest of the paper is organized as follows: Section 2 briefly presents the methodology used, followed by the system proposed for supplier evaluation which is based on several multiple criteria approaches, compensatory and non-compensatory. This system has been validated in a real company for food, pharmaceuticals and chemicals, as explained in section 4 . In this section all criteria related to products and suppliers have been defined and grouped in two new dimensions: critical and strategic. The strategic criteria consider internal factors of production, while the critical criteria refer to market information. The main results obtained by applying PROMETHEE and MAUT are shown in section 5 and finally their discussion and conclusions are presented in the last two sections respectively. 


\section{Methodology}

When companies want to evaluate and classify their suppliers in order to highlight appropriate relationships between them, they first need to identify the criteria to be used to measure their performance. The well-known AHP method allows defining and building a hierarchy with all criteria, grouping them into categories, if necessary. This can be done by a manager and also collaboratively by a group of decision makers or stakeholders. The next step is to elicit the weights of criteria to be used in the evaluation.

AHP obtains the weights of criteria through pairwise comparisons of these on the same level with respect to a criterion on the higher level. For example, the company has defined several types of risks, such as commercial risk and risk of the supplier country as evaluation criteria and has grouped them into a category "critical criteria". In this case the type of questions to answer is the following: how much greater is the importance of commercial risk compared to the risk of the supplier country with respect to the critical criteria of suppliers? A detailed explanation of AHP method can be found in Saaty \& Vargas (2001). This method allows the company to elicit the weights, which show their preferences and measure the consistency of the judgements. Moreover, it is easy to apply in order to aggregate the preferences from different people and departments of the company by using the geometric mean (Saaty \& Peniwati, 2008).

Due to a finite number of suppliers to be evaluated and classified, two discrete multiple criteria methods have been chosen among available techniques, which can be classified as compensatory and non-compensatory approaches. The system proposed includes MAUT as compensatory and PROMETHEE as non-compensatory method. Since both types have strengths and weaknesses, it is interesting to compare them for supplier segmentation.

In addition to the criteria and their weights, PROMETHEE needs indicators $\mathrm{g}_{\mathrm{j}}$ to measure the performance of each supplier for each criterion, as can be seen in the evaluation table (Table1). PROMETHEE compares every pair of suppliers for each criterion and assigns a preference value, taking into account the size of the difference in the behaviour of the suppliers: $d_{j}\left(s_{1}, s_{2}\right)$ $=g_{j}\left(s_{1}\right)-g_{j}\left(s_{2}\right)$. This method removes the scale effect when the criteria are measured in different units.

Table 1. Evaluation Table

\begin{tabular}{|c|c|c|c|c|c|c|}
\hline \multirow{2}{*}{ Suppliers } & \multicolumn{6}{|c|}{ Indicators of evaluation criteria } \\
\hline & $\mathrm{g}_{1}$ & $\mathrm{~g}_{2}$ & $\ldots$ & $\mathrm{g}_{\mathrm{j}}$ & $\ldots$ & $\mathrm{g}_{\mathrm{k}}$ \\
\hline $\mathrm{s}_{1}$ & $\mathrm{~g}_{1}\left(\mathrm{~s}_{1}\right)$ & $\mathrm{g}_{2}\left(\mathrm{~s}_{1}\right)$ & $\ldots$ & $\mathrm{g}_{\mathrm{j}}\left(\mathrm{s}_{1}\right)$ & $\ldots$ & $\mathrm{g}_{\mathrm{k}}\left(\mathrm{s}_{1}\right)$ \\
\hline $\mathrm{S}_{2}$ & $\mathrm{~g}_{1}\left(\mathrm{~s}_{2}\right)$ & $\mathrm{g}_{2}\left(\mathrm{~s}_{2}\right)$ & $\ldots$ & $\mathrm{g}_{\mathrm{j}}\left(\mathrm{s}_{2}\right)$ & $\ldots$ & $\mathrm{g}_{\mathrm{k}}\left(\mathrm{s}_{2}\right)$ \\
\hline$\ldots$ & $\ldots$ & $\ldots$ & $\ldots$ & $\ldots$ & $\ldots$ & $\ldots$ \\
\hline $\mathrm{S}_{\mathrm{i}}$ & $\mathrm{g}_{1}\left(\mathrm{~s}_{\mathrm{i}}\right)$ & $\mathrm{g}_{2}\left(\mathrm{~s}_{\mathrm{i}}\right)$ & $\ldots$ & $\mathrm{g}_{\mathrm{j}}\left(\mathrm{s}_{\mathrm{i}}\right)$ & $\ldots$ & $\mathrm{g}_{\mathrm{k}}\left(\mathrm{s}_{\mathrm{i}}\right)$ \\
\hline$\ldots$ & $\ldots$ & $\ldots$ & $\ldots$ & $\ldots$ & $\ldots$ & $\ldots$ \\
\hline$S_{n}$ & $\mathrm{~g}_{1}\left(\mathrm{~s}_{\mathrm{n}}\right)$ & $\mathrm{g}_{2}\left(\mathrm{~s}_{\mathrm{n}}\right)$ & $\ldots$ & $\mathrm{g}_{\mathrm{j}}\left(\mathrm{s}_{\mathrm{n}}\right)$ & $\ldots$ & $\mathrm{g}_{\mathrm{k}}\left(\mathrm{s}_{\mathrm{n}}\right)$ \\
\hline
\end{tabular}


In general, when a supplier $s_{1}$ is compared to $s_{2}$ for each criterion $g_{j}$ the company defines a preference function, $P_{j}\left(s_{1}, s_{2}\right)$, which depends on the difference in the behaviour of both suppliers:

$$
\begin{aligned}
& \boldsymbol{P}_{\boldsymbol{j}}\left(s_{1}, s_{2}\right)=\boldsymbol{F}_{\boldsymbol{j}}\left[\boldsymbol{d}_{\boldsymbol{j}}\left(s_{1}, s_{2}\right)\right] \text { for all suppliers, where } \\
& \boldsymbol{d}_{\boldsymbol{j}}\left(s_{1}, s_{2}\right)=\boldsymbol{g}_{\boldsymbol{j}}\left(s_{1}\right)-\boldsymbol{g}_{\boldsymbol{j}}\left(s_{2}\right) \text { and } \\
& \boldsymbol{0} \leq \boldsymbol{P}_{\boldsymbol{j}}\left(s_{1}, s_{2}\right) \leq \boldsymbol{1}
\end{aligned}
$$

In case the criterion is maximized and the difference is negative, the preference is 0 . When we want to minimize the criterion, it would be other way round or we consider the preference function as follows:

$$
\boldsymbol{P}_{j}\left(s_{1}, s_{2}\right)=\boldsymbol{F}_{j}\left[-\boldsymbol{d}_{j}\left(s_{1}, s_{2}\right)\right]
$$

The company must propose a preference function for each criterion. The most common functions are the following: it is known as usual when the preference is 1 if the difference between the performance of $s_{1}$ and $s_{2}$ is positive, and zero otherwise. We have to define one or two parameters in other types of preference functions. We call the indifference threshold $q$ and the strict preference threshold p. q is the largest deviation between two criterion values in the pairwise comparison of the suppliers that the company considers as negligible, while the preference threshold $\mathrm{p}$ is the smallest value of this deviation to be considered as sufficient for a strict preference of one supplier over the other. Depending on the type of preference function, its value $P j\left(s_{1}, s_{2}\right)$ can be 0,1 or increase linearly between the indifference threshold and strict preference threshold from zero to 1(linear functions). A detailed explanation of PROMETHEE can be seen in Brans \& Mareschal (2005).

The other approach used is based on the value measurement theory whose full description can be found in Belton and Stewart (2003). In short, the well-known additive model of value function is represented as follows:

$$
V(s)=\sum_{i=1}^{m} w_{i} v_{i}(s)
$$

where $\mathrm{V}(\mathrm{s})$ is the overall value or utility of a supplier, $\mathrm{v}_{\mathrm{i}}(\mathrm{s})$ is the value or utility score that corresponds to the performance on criterion $\mathrm{i}$ of the supplier $\mathrm{s}$, and $\mathrm{w}_{\mathrm{i}}$ is the weight which shows the importance of criterion i. It is interesting to point out that this approach, unlike PROMETHEE, provides scores based only on the own performance of suppliers. Thus, these scores are independent of other suppliers included in the assessment. Some of the advantages and disadvantages of value function and outranking methods come from this fundamental difference. 


\section{A collaborative multiple criteria system for supplier evaluation}

The companies can reduce risks if they acquire the same product from a few reliable suppliers. In general vendors provide the company with several products and the same product is served by different suppliers. Thus the assessment of products is not equivalent to the evaluation of suppliers, being the latter an open and much more complex problem. Figure 1 shows the flowchart for the new system of supplier management that considers both products and suppliers.

The company should starts the process by identifying the pertinent departments that should be involved in the supplier evaluation for each group of products, as recommended by Gelderman \& Van Weele (2003), for example chemical, packaging, electronic, mechanical, etc. or any other specific type of products. Purchasing, quality, production and/or maintenance are some possible departments depending on the business. It is also necessary to define the people who will participate in the assessment. After establishing the criteria to evaluate if a supplier is qualified for a product, the company can apply a systematic procedure to perform this assessment. MAUT is an appropriate compensatory method to qualify suppliers and then also rank them in order to choose the better options for purchasing.

To assess all approved suppliers it is necessary to identify the criteria that are specific of the products they provide, as well as the indicators to measure their performance. The system proposes to group these criteria according to their internal and external nature. On the one hand, the market of the products is an external factor which can make them critical for the production process. On the other hand, internal features of some products can make them strategic for the company. Thus, all criteria used to evaluate products are grouped into two categories: critical and strategic, depending on if they are mainly related to the market for the former and affect internal operations of the factory for the latter. For example, external criteria of products can be safety and environment regulations as well as the number of suppliers. These criteria might make products critical. The strategic criteria are, for example, contact with the final product and if the product can stop the factory production.

The next step is to elicit the criteria weights for product assessment. This may be done by consensus of people involved or by using AHP. This method can be applied collaboratively or individually, followed by integrating individual judgments to calculate the weights of the criteria to be used in the company (Saaty and Peniwati, 2008). 


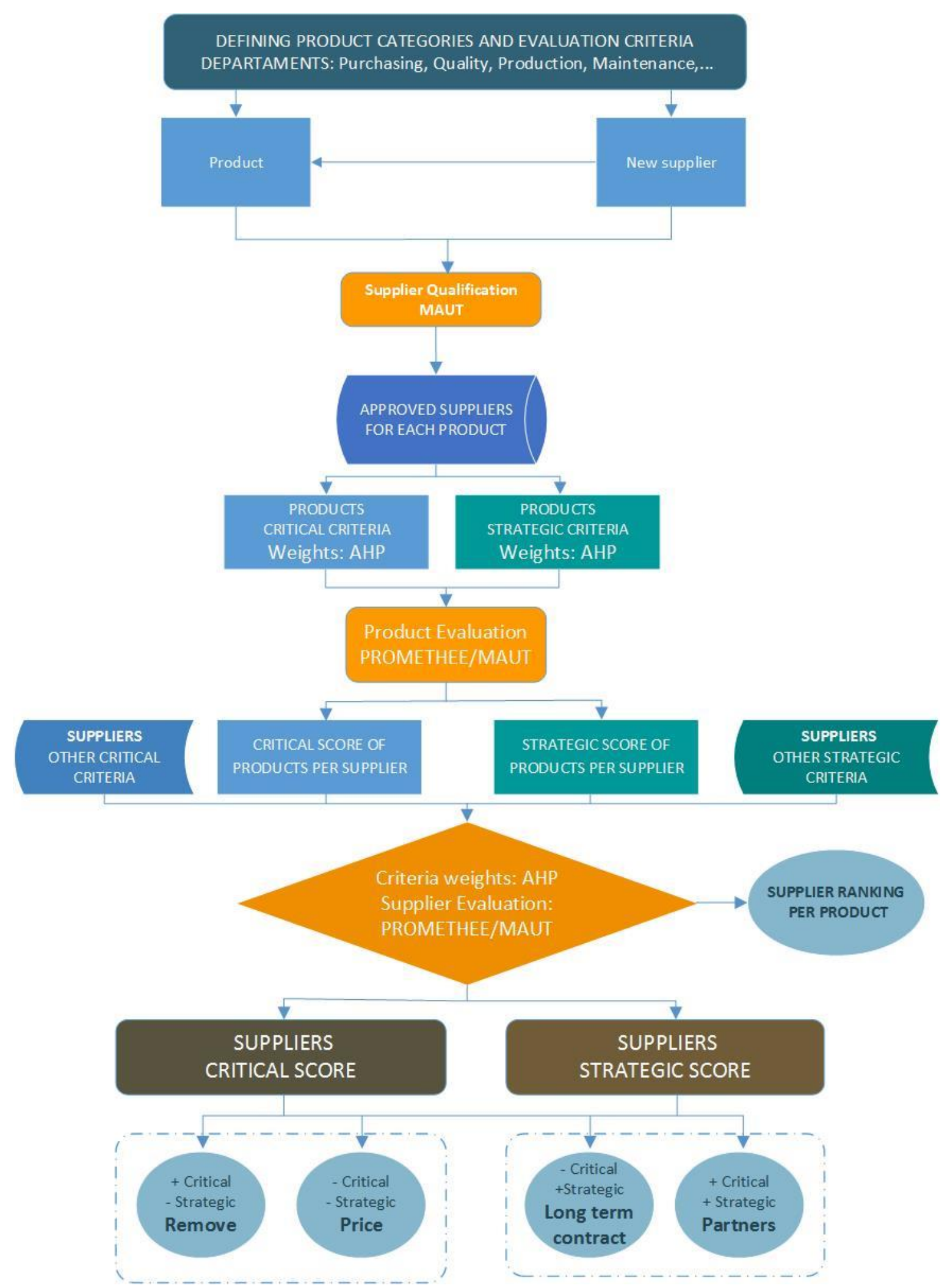

Figure 1. Flowchart of collaborative multiple criteria system for supplier evaluation 
By applying PROMETHEE or MAUT, critical score and strategic score are obtained in order to assess the suppliers according to their critical or strategic nature for the company. Both methods need an evaluation table (Table 1) which shows the indicators of evaluation criteria for each product or supplier depending on the step of the procedure shown in figure 1.

The critical and strategic scores of products are values between zero and 100 and can be calculated by using PROMETHEE or MAUT. The company can generate a graphic tool to classify the products by representing these scores together with the purchase volume for every product in a bubble graph, where the axes are critical and strategic scores and the size of the bubble is the billing. As in Kraljic's model, the products can be classified in four areas taking into account their scores, for example if they are lesser or greater than 50. This graph highlights the critical and strategic nature of products and informs about the best actions to be implemented. The purchasing department should mainly focus on those which appear in the area with greatest critical and strategic nature (a small number of suppliers, long delivery times, low safety level, items which have contact with the final product and/or can stop the production of the company). There is an area where the products are not critical, but they are very strategic, so the company should look for the best provisioning method for them. When the product is hardly strategic nor critical, the purchasing management by price is recommended. Finally, the fourth area in the graph presents the products which are hardly strategic but very critical, which is similar to bottleneck area in the Kraljic's model for items. In this case the management should analyse the situation carefully to decide on actions related to these products and look for less critical alternatives among other possibilities.

Although this analysis of items is important, currently the interest of companies is focused on supplier classification. Thus, after evaluating the products, suppliers can be evaluated with a similar methodology. First of all, identifying the main critical and strategic criteria and those directly related to supplier is needed. The average critical score of products is a critical criterion to evaluate suppliers. Delays and commercial risk can be other critical criteria. Similarly the strategic score of products is a criterion used to calculate the strategic score of suppliers, among other criteria, such as purchase volume.

After defining the complete hierarchy of criteria to evaluate suppliers and grouping them as critical and strategic, the weights of criteria are calculated by involving the pertinent people and by applying AHP. The weights can also be obtained individually and aggregated through the geometric mean. Then, PROMETHEE and/or MAUT method are used to obtain the critical and strategic scores of suppliers. These results have twofold purposes. The company can obtain the ranking of suppliers for each product individually and also classify them for each group of products in order to decide about the type of relationship to establish with them.

As in the products, critical and strategic scores of suppliers together with their purchase volume are shown in a bubble graph, which uses 50 as the value of both scores to divide the space into four areas. This graph permits the company to classify their suppliers and establish the appropriate relationship with each of them. The most important suppliers are those who are very critical and strategic and should be partners of the company. The company should sign long term contracts with the suppliers that are not critical, but very strategic, while price policy is recommended when the providers are hardly strategic and hardly critical. Finally, the company should remove those suppliers with low strategic but high critical nature. 


\section{Supplier evaluation in a real manufacturing industry}

The proposed system has been implemented in a real manufacturing factory. The company is a multinational industry active in more than 100 countries and in several sectors such as food, pharmaceuticals and chemicals, among others. The company manufactures a wide range of products in the fields of human nutrition, pharmacy-cosmetology, paper/board, chemistry-bio industry and animal nutrition.

The company has a purchasing and warehouse management module of the SAP ERP software. Nevertheless, this system does not provide them with techniques to manage the supplier portfolios which involve a high number of products and vendors. Previously the company only assessed acquired products. These products were analysed according to their risks following the Kraljic's model without taking into account their suppliers. Assessments were carried out quarterly and data from previous three years were used. This methodology had some drawbacks, such as the aggregation of criteria measured in different units and several trial and error tests to obtain the weights. As a result this procedure was not able to distinguish among very different products which obtained similar performance values.

\subsection{Modelling preferences for product criteria: AHP, PROMETHEE and MAUT}

As shown in figure 1, in the first step product categories were defined as follows: chemical, packaging and technical products (electrical, electronic, pneumatic, mechanical, hydraulic, etc.). This empirical research is focused on the two first groups, chemical and packaging products, whose number is close to 200 in the factory. In addition, all data used are real and related to products from approved suppliers, since qualifying suppliers is a particular case of supplier evaluation for a unique product.

First of all, AHP method was used for building the hierarchy with the main critical and strategic criteria which are specific of the products. The critical criteria are mainly related to the market, and strategic criteria are those which are affecting internal operations of the factory. As shown in figure 2, critical criteria of products are safety and environmental regulations, number of suppliers, delivery time and provisioning factor. The strategic criteria are contact with the final product, stopping the production of the factory, affect the image of the company and the purchase volume.

The weights of criteria have been obtained by applying AHP method collaboratively, with the well-known Saaty scale for pairwise comparisons (Saaty \& Vargas, 2001). Global weights can also be obtained from individual matrices of pairwise comparison and then by applying the geometric mean to judgments and finally with Eigen Vector method to elicit the weights for the team involved in the assessment (Saaty \& Peniwati, 2008; Ishizaka \& Labib, 2011). 


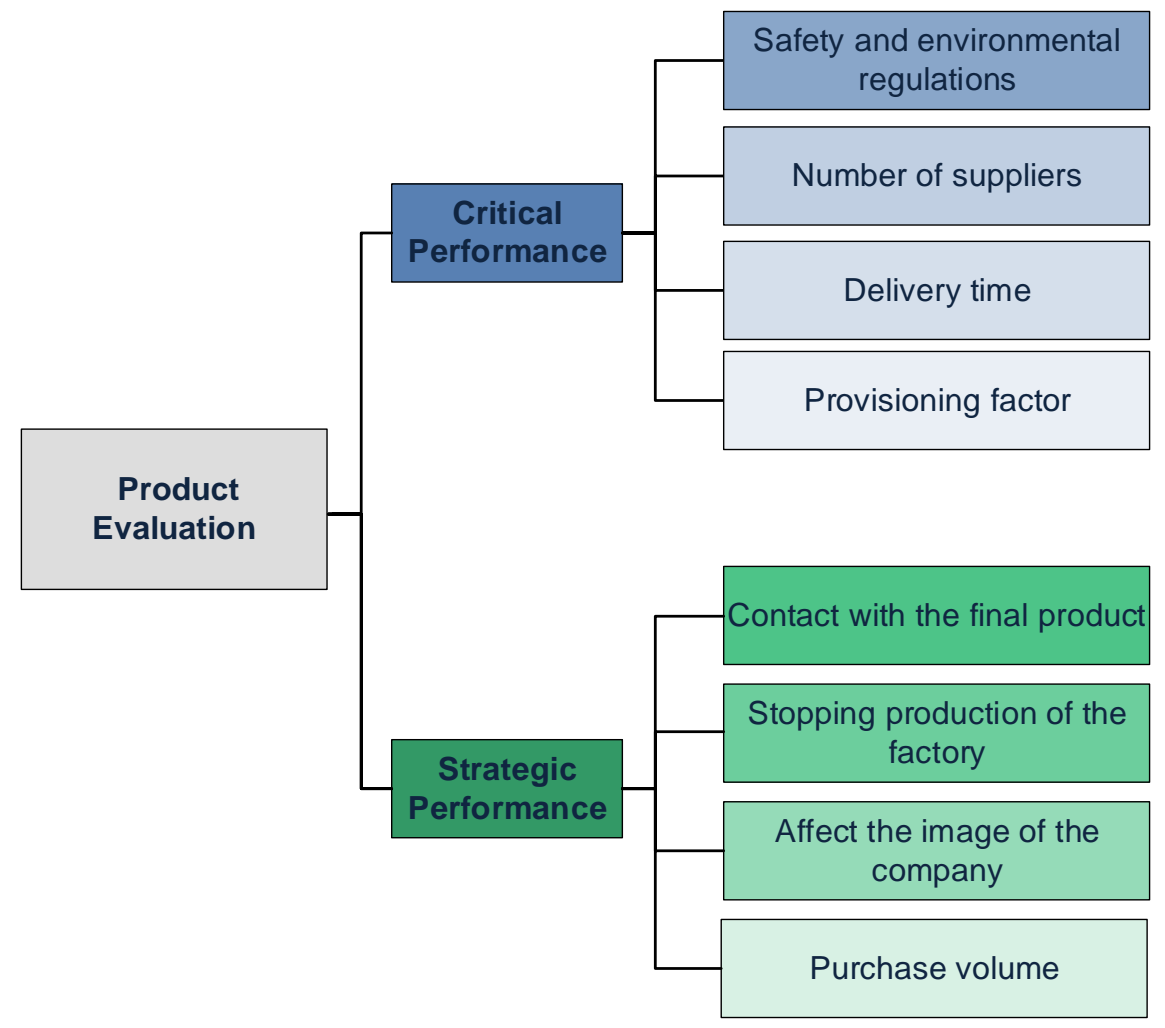

Figure 2. Hierarchy for critical and strategic criteria of products

After that, it is necessary to define how to measure the performance of criteria, known as indicators, and to model the preferences for decision making in order to apply PROMETHEE and MAUT, being the former an outranking method, that is non-compensatory, and the latter compensatory.

To explain and understand the real application of PROMETHEE it is necessary to get information about the scales and preference functions which have been used. Firstly, the products are evaluated through indicators which can be measured in quantitative or qualitative scales. For example, the purchase volume (euros) and the delivery time (days) are quantitative indicators, while some others are qualitative, such as stopping production of the factory. This last criterion is measured in a qualitative scale that we convert into numbers from 1 to 5 . Its value is 1 when the lack of product can stop the production completely, 2 if its lack can stop the factory partially, 3 if it may cause the failure of a sector, 4 if it can affect production, but there is an alternative and 5 when the lack of product does not affect the factory production.

Contact with the final product and affect the image of the company are criteria which use similar scales from 1 to 5, being 1 the worst and 5 the best situation for the company. In particular, if the product has direct contact with the final product, the indicator value is 1,2 if it has occasional direct contact, 3 when there is indirect contact, 4 if the contact is occasional indirect and finally, 5 when the product does not have any contact with the final product.

The meaning of the scale related to the effect of the product on the image of the company is as follows: 1 when the product affects the image, 3 if the effect is indirect and 5 when the product does not affect the image of the final product. 
Some criteria, such as safety and environmental regulations, are maximized while others are minimized, for example delivery time. The indicator of safety and environmental regulations is the degree of compliance with the specific regulations, expressed in percentage.

The preferences of the decision makers are considered by PROMETHEE in the weights of criteria and also in the preference functions (Brans \& Mareschal, 2005). When usual preference function is used for a criterion, its maximum value, which is equal 1 (strict preference), is assigned to the product with the best indicator value. This research has considered the usual preference function for the criteria with qualitative scales that are contact with the final product, stopping production of the factory and affect the image of the company.

The preference function for the remaining criteria is linear. For example, when comparing two products with respect to the delivery time, the preference is increasing linearly for what has lesser delivery time from 0 up to a difference of 50 days. For higher values the strict preference is for the better product which is the one that has shorter delivery time because the objective is to minimize this criterion. The same preference function was used for provisioning factor. In case of safety and environmental regulations, the preference function is also linear with zero as indifference threshold and 100 as strict preference threshold.

Linear preference function has also been used for the purchase volume with an indifference threshold of 50,000 euros and a strict preference threshold of 1,000,000 euros. This means that the preference function is zero when the difference between the purchase volume of two products is lesser than 50,000 euros, while the preference function increases linearly from zero to 1 when that difference goes up from 50,000 to one million euros.

Sometimes it is necessary to look for an appropriate indicator of a criterion so that a preference function of PROMETHEE captures real preferences of decision makers. In this research the number of suppliers is a good example. The greater the number of suppliers, the better for the company, 5 being the optimal number. Nevertheless, it is more preferable to increase the number of suppliers from 1 to 2 rather than from 4 to 5 . The linear preference function for the number of suppliers, a criterion that should be maximized, does not take into account this consideration. So, the inverse of the number of suppliers multiplied by 100 is used as an indicator along with linear preference function. Hence, its value is equal to 100 in case of 1 supplier, 50 for 2 suppliers, 33 for 3, 25 for 4, and 20 for 5 suppliers. The preferences of the company are well represented by considering 5 as Indifference Threshold and 50 as Preference Threshold. Thus the objective is to minimize the inverse of the number of suppliers.

In order to compare PROMETHEE with MAUT the same data of criteria have been used, including the inverse function of the number of suppliers, although it is not necessary in MAUT. In addition we have tried to represent the preferences of decision makers as similar as possible by means of utility functions in MAUT and preference functions in PROMETHEE. Nevertheless, the different nature of these methods makes it impossible to say that they are equivalent completely. The scale of utility function for all criteria in MAUT is from 0 to 100 . 


\subsection{Modelling preferences for supplier criteria: AHP, PROMETHEE and MAUT}

The assessment of a supplier should take into account the critical and strategic performances of their products. Thus, the hierarchy shown in figure 3 includes the critical score of products as a criterion whose indicator is the mean of critical scores of the products per supplier. The critical performance of suppliers also includes other four criteria: delays, commercial risk, risk of the supplier country and risk of the supplier billing. The strategic performance of suppliers takes into account the mean strategic score of their products, as well as the purchase volume to the supplier over total purchases of the company.

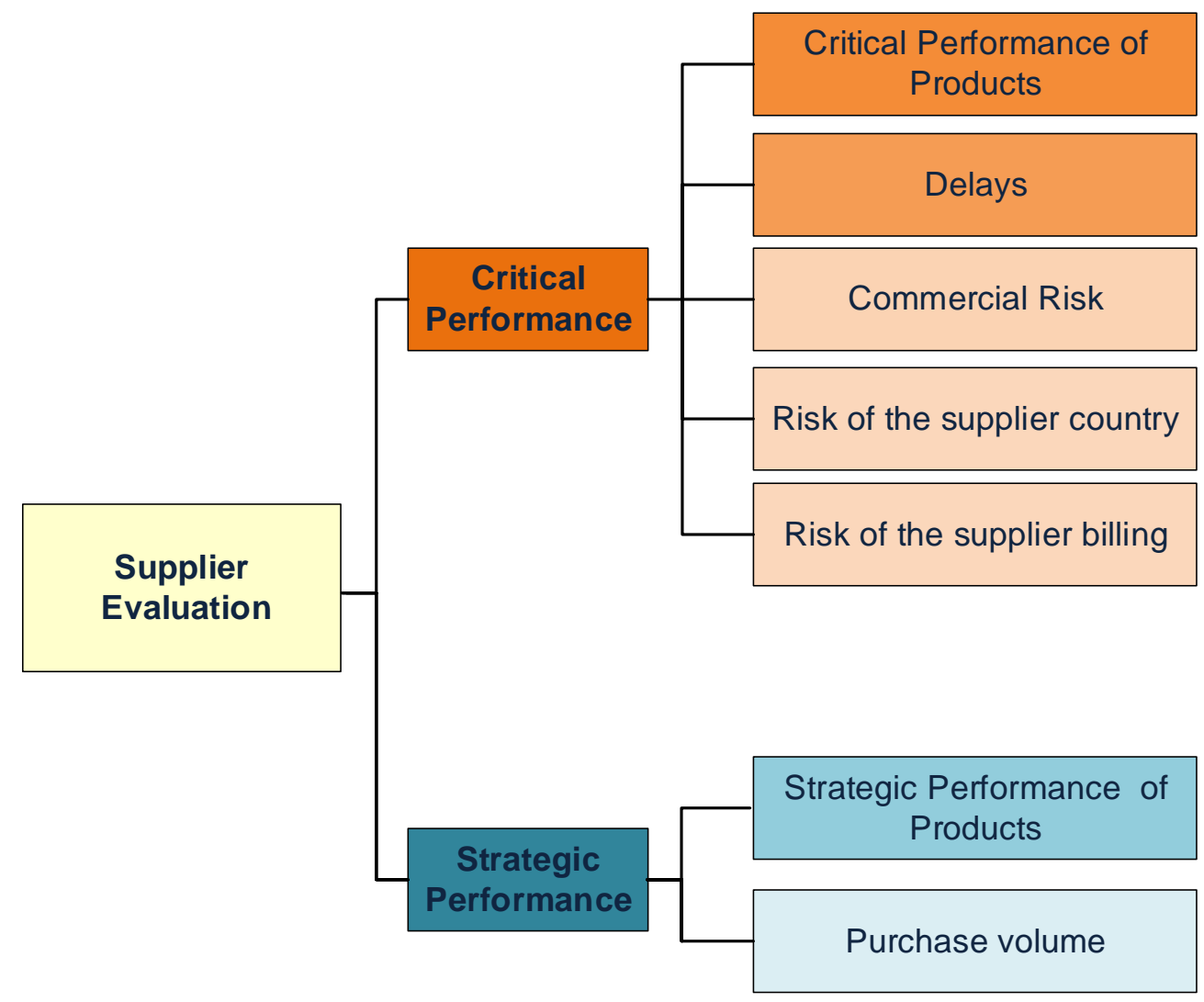

Figure 3. Hierarchy for critical and strategic criteria of suppliers

The methodology in applying AHP, PROMETHEE and MAUT to evaluate suppliers is similar to the one previously explained for products. AHP has also been used to weight the criteria by group decision making. Then PROMETHEE and MAUT allow ranking suppliers by product and classifying the suppliers according to their critical and strategic nature.

In this case the usual preference function was used for commercial risk and risk of the supplier country. The indicator for the commercial risk is the rating developed by an expert company (e-informa) based on 180 parameters, which uses a scale from zero to 20. Companies can have high commercial risk (1-6), medium-high (7-10), medium-low (11-15) and very low risk (16$20)$. When zero is assigned to a company, it has a very difficult commercial and legal situation. 
The indicator for risk of the supplier country is based on the rating of countries from an expert company (Coface). The scale is from 1 to 7,1 for the best situation when the prospects are favourable and stable and the probability of company default is very low. The value 7 means unstable and uncertain prospects with very high probability of company default.

The remaining critical criteria of suppliers have quantitative indicators, so linear preference function was used. In particular, indifference threshold is zero for critical performance of products and delays, while their preference threshold are 10 and 50 respectively. The risk of supplier billing measures the percentage of the supplier sales to the company with respect to total sales of the supplier. In this case the company uses 2 as indifference threshold and 15 as strict preference threshold.

Referring to the strategic criteria of suppliers both are quantitative and a linear preference function was used in PROMETHEE. The indifference threshold is zero for strategic performance of products and 2.3 for purchase volume which is measured by the percentage of the sales of the supplier with respect to the total purchases of the company. Their preference thresholds are 10 for the former criterion and 20 for the latter.

The utility functions for each criterion used in MAUT capture similar information to those of preference functions established in PROMETHEE. After applying PROMETHEE and MAUT the company can easily analyse the performance of their suppliers by product as in other portfolio models. Nevertheless, one of the main contributions of this empirical research is to classify the suppliers according to new dimensions, their critical and strategic nature, as well as to explore and compare the strengths and weaknesses of the two main types of multiple criteria approaches, outranking and value functions methods, for supplier segmentation. The main results are presented in the next section. 


\section{Results}

\subsection{Weights of criteria}

Based on the categories of critical and strategic criteria of products and suppliers and the involvement of a group of people from the purchasing department of the factory, the weights used for supplier evaluation are those shown in table 1 . These weights have been obtained by applying AHP as explained in the previous section.

Table 2. Weights of criteria in the evaluation of products and suppliers

\begin{tabular}{llll}
\hline Evaluation & Category & Criterion & Weight \\
\hline \multirow{4}{*}{ Critical } & Safety and environmental regulations & 55.2 \\
& & Number of suppliers & 32.7 \\
& & Delivery time & 7.4 \\
& & Provisioning factor & 4.7 \\
& & Total & 100.0 \\
\cline { 3 - 4 } & \multirow{4}{*}{ Strategic } & Contact with the final product & 45.0 \\
& & Stopping production of the factory & 32.1 \\
& Affect the image of the company & 14.2 \\
& Purchase Volume & 8.7 \\
& & Total & 100.0 \\
\hline \multirow{4}{*}{ Suppliers } & Critical performance of products & 49.10 \\
& & Delays & 22.6 \\
& & Commercial Risk & 11.1 \\
& & Risk of the supplier country & 6.5 \\
& & Risk of the supplier billing & 10.7 \\
& & Total & 100 \\
\cline { 3 - 4 } & \multirow{2}{*}{ Strategic } & Strategic performance of products & 85.0 \\
& & Purchase Volume & 15.0 \\
& & Total & 100.0 \\
\hline
\end{tabular}

As shown in table 2, safety and environment regulations and the number of approved suppliers are the most important critical criteria, while the contact with the final product and stopping production of the factory are the most relevant strategic criteria in the first phase related to performance evaluation of products. When supplier evaluation is carried out the critical performance of products and delays have the highest weights, while the strategic performance of products has almost all the importance of the strategic criteria in the supplier evaluation. 


\subsection{Critical and strategic performance of suppliers}

This section shows the most relevant results of multiple criteria analysis based on real data from 162 products and 67 suppliers, carried out with historical data of a factory from the last three years. Products and suppliers appear recoded in order to facilitate the presentation, and also due to confidentiality reasons. The critical and strategic scores of products and suppliers have been obtained applying PROMETHEE and MAUT by using D-Sight CDM software (2016).

\subsubsection{Classifying suppliers with PROMETHEE}

Since the most important criteria for supplier evaluation are critical and strategic score of products, it is necessary to calculate them for products previously. Figure 4 shows the score of critical performance of products obtained by PROMETHEE.

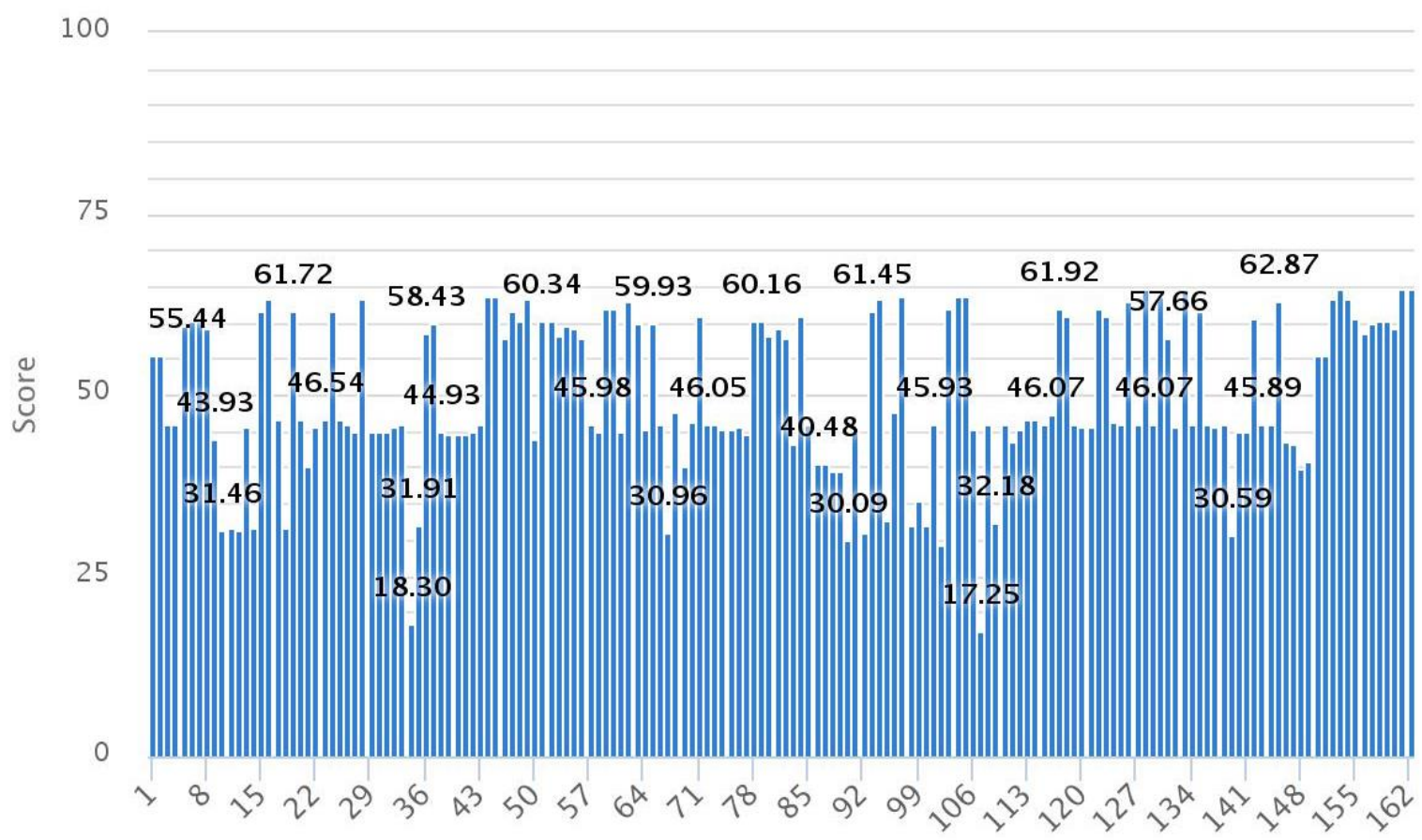

Figure 4. Scores for critical performance of products obtained by PROMETHEE. Products from 1 to 162

According to historical data the number of products by supplier varies between 1 and 7. So, first the mean of critical scores of the products by each supplier is calculated, and then the result is used as the indicator in the supplier evaluation as shown in figure 3 . The same applies to strategic performance of products.

Then, the next step is to determine the score for the critical and strategic performance of suppliers. The contribution of criteria to the score for critical performance of suppliers is shown in Figure 5, where critical performance of products represents the greatest contribution and risk of supplier country the lowest. 


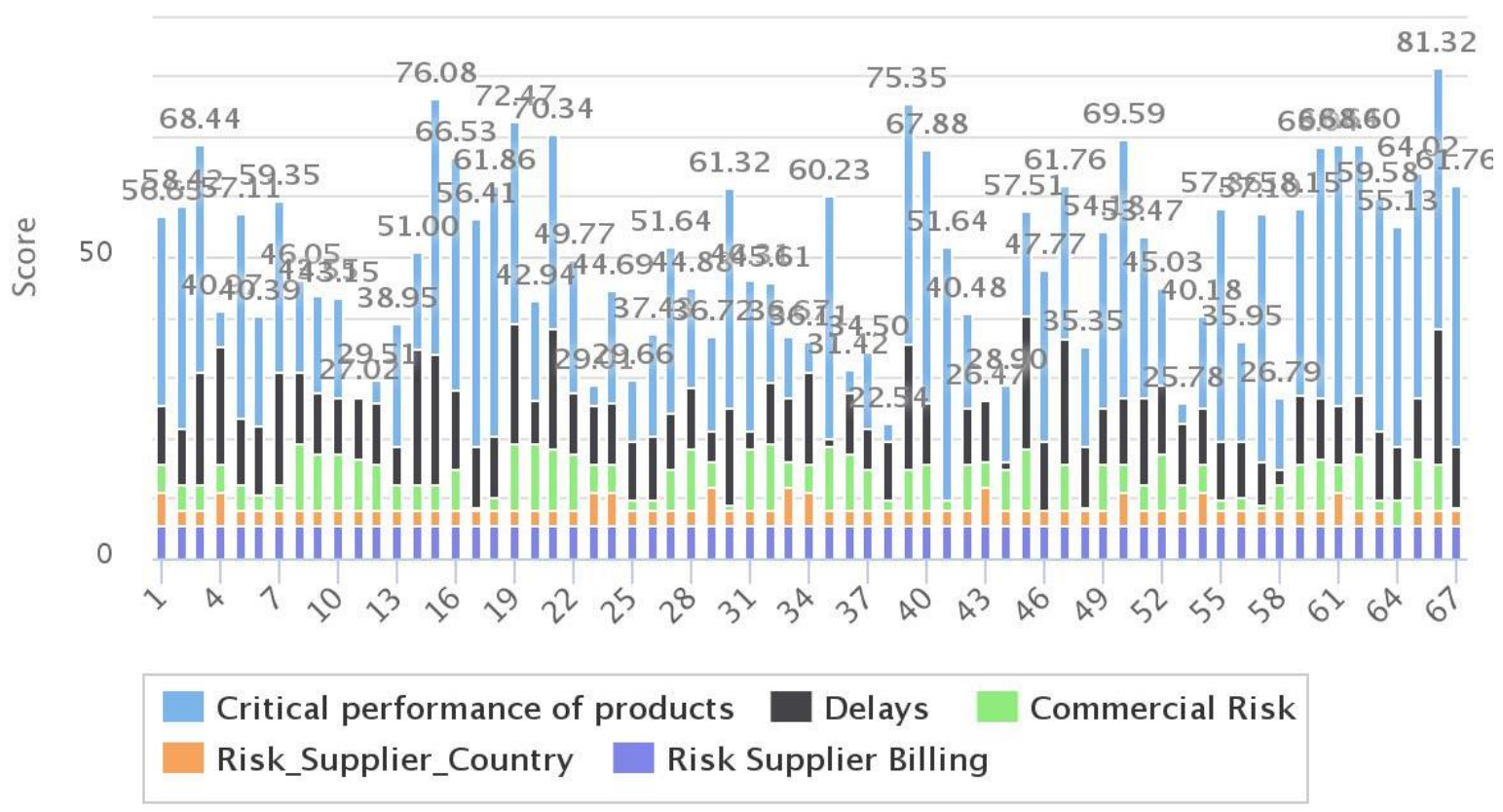

Figure 5. Criteria contribution to the score for critical performance of suppliers obtained by PROMETHEE. Suppliers from 1 to 67

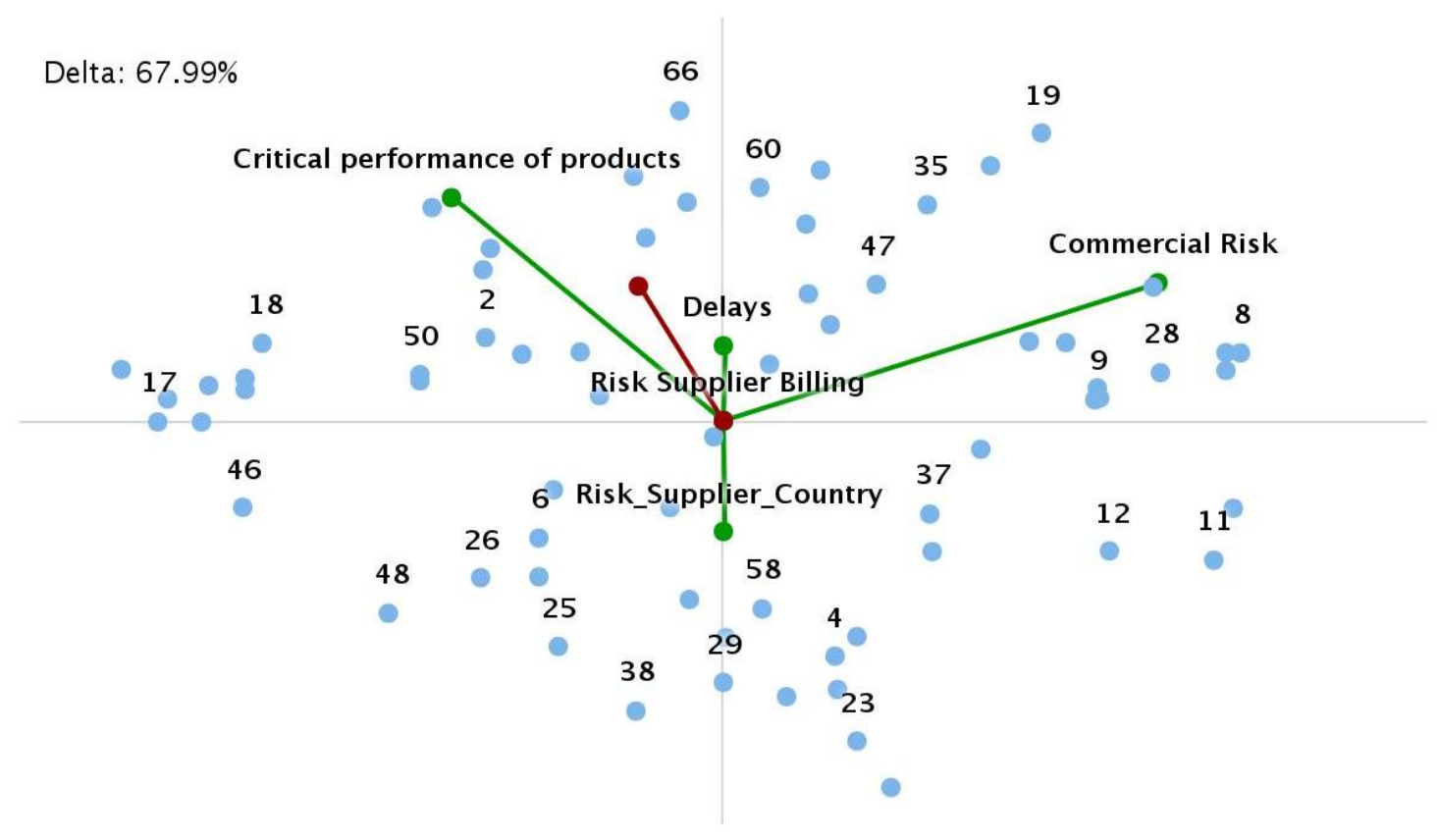

Figure 6. Global visual analysis for critical performance of suppliers obtained by PROMETHEE. Suppliers from 1 to 67 
Figure 6 represents the Geometrical Analysis for Interactive Aid (GAIA) plane, a relevant graphic tool for analysing multiple criteria problems (Brans \& Mareschal, 2005). The criteria are the green axes and the points are the suppliers. The longer the axis, the more discriminant is a criterion. The red axis would indicate the decision if we solved a supplier selection problem, but this is not the case.

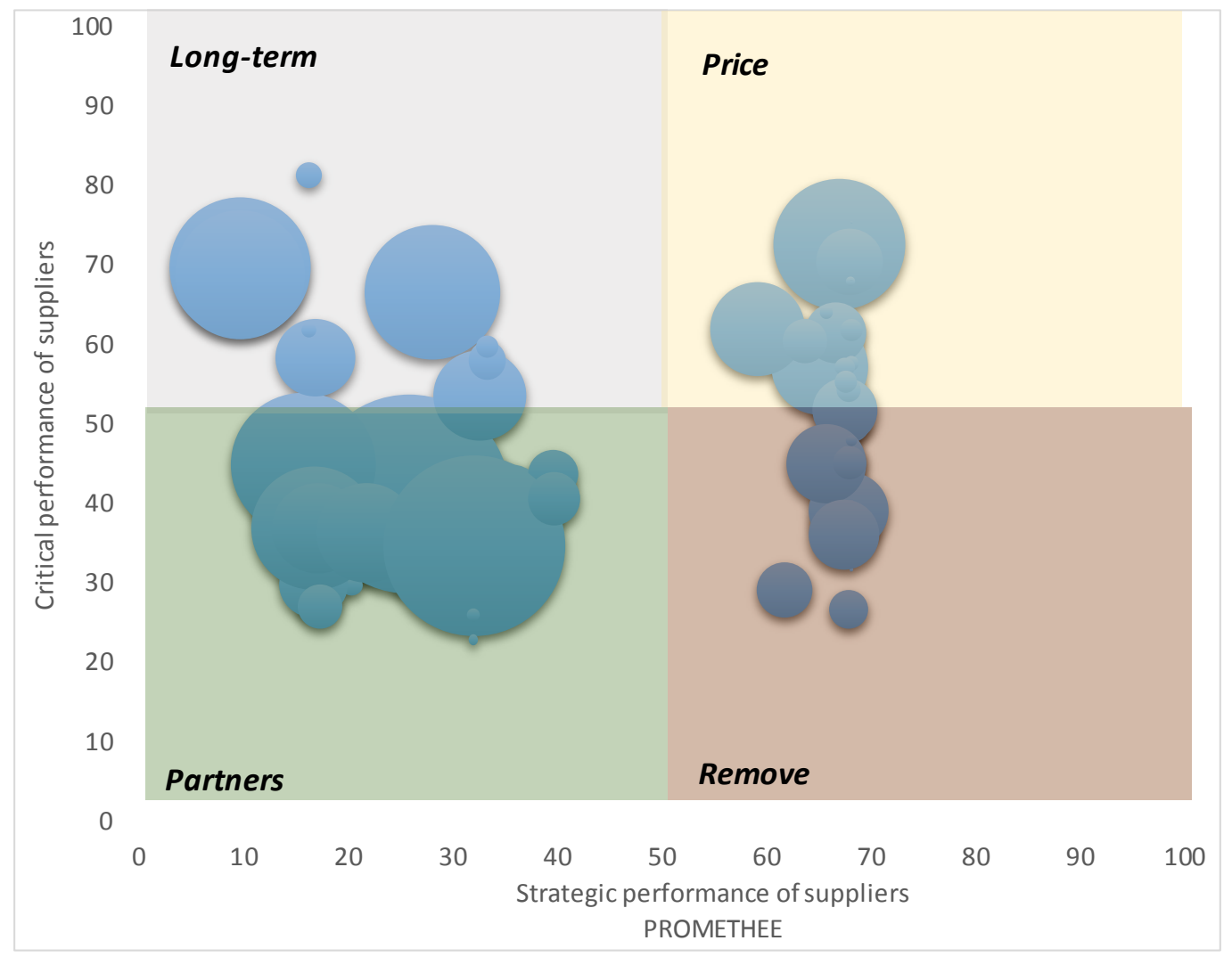

Figure 7. Classification of suppliers according to their critical and strategic performance. PROMETHEE. Bubble size represents the purchase volume of supplier. The higher the score, the better

The joint representation of the results from supplier evaluation is shown in figure 7 . The $\mathrm{x}$-axis is the strategic score and the $y$-axis the critical score of the suppliers. The size of bubbles shows the purchase volume. The graph is divided into four areas at the value 50 for both axes whose meaning is as follows: the higher the score, the better. The suppliers with critical and strategic scores over 50 have good performance and will be less critical and strategic. Therefore, the appropriate relationships between the company and these suppliers should be guided by market price and moving these suppliers to other quadrants in the figure 7 is not always interesting for the company. On the contrary, the very critical and very strategic suppliers are those with low values in both axes. These suppliers should be partners because they have great critical and strategic nature for the company. In other words, they provide critical items associated also to delays and several market and supplier risks, as well as items which affect the internal operations of the factory in a great extent. In this case, the company could also be interested in looking for other alternative suppliers, moving the supplier onto another quadrant of the figure 7, as Gelderman and Van Weele indicated (2003). When suppliers maintain strategic character, but they are not critical, one suitable strategy for the company to follow is to sign long term contracts. Finally, when a supplier has a low critical score, but a high strategic score, this 
provider is very critical but little strategic for the company. Therefore, this supplier would have to be removed from the portfolio or both parts take actions in order to improve its critical performance in a similar way to bottleneck area from Kraljic's model, and move on the noncritical quadrant. All these recommendations have to be based on the analysis of systematic and continuing evaluations of the suppliers, such as monthly evaluations, quarterly or annually, in order to test and verify the evolution of supplier performance.

\subsubsection{Classifying suppliers with MAUT}

The global visual analysis of critical performance of suppliers obtained by MAUT is presented in figure 8 in order to compare this method with PROMETHEE. Figures 6 and 8 highlight the additive model of MAUT and the outranking nature of PROMETHEE. This can also be seen in figure 9, which shows critical and strategic scores together. Comparing the supplier evaluation through the new graph proposed, figures 7 and 9, highlights higher scores obtained with MAUT in both critical and strategic performances.

Delta: $86.98 \%$

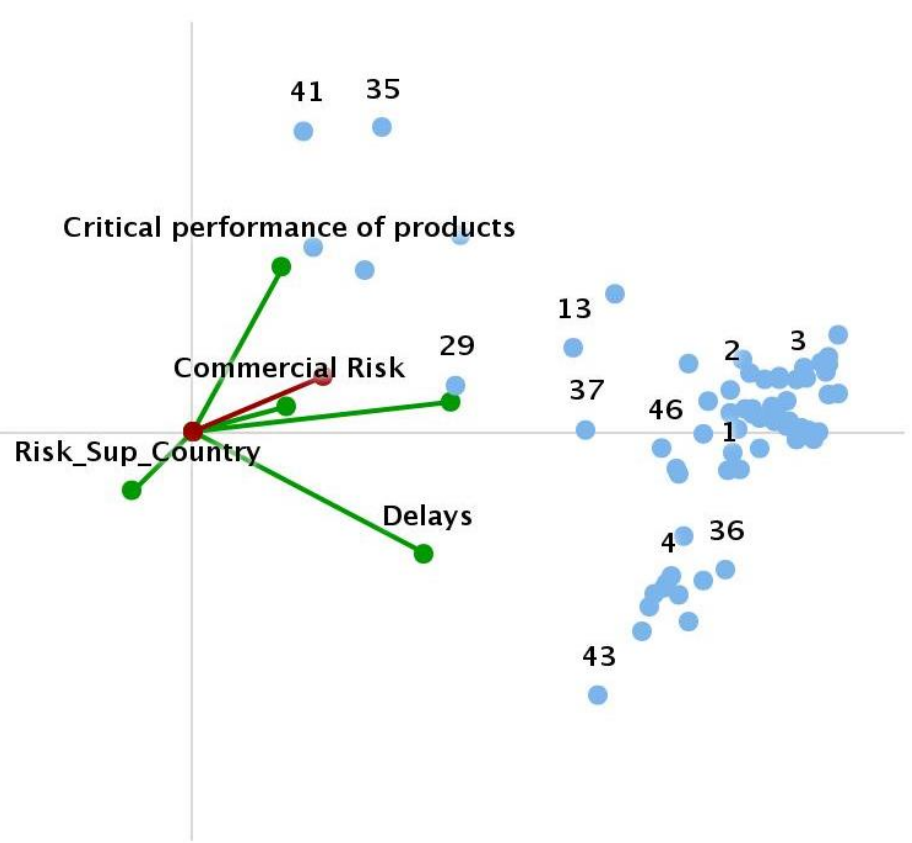

Figure 8. Global visual analysis for critical performance of suppliers obtained by MAUT. D-Sight CDM Suppliers from 1 to 67 


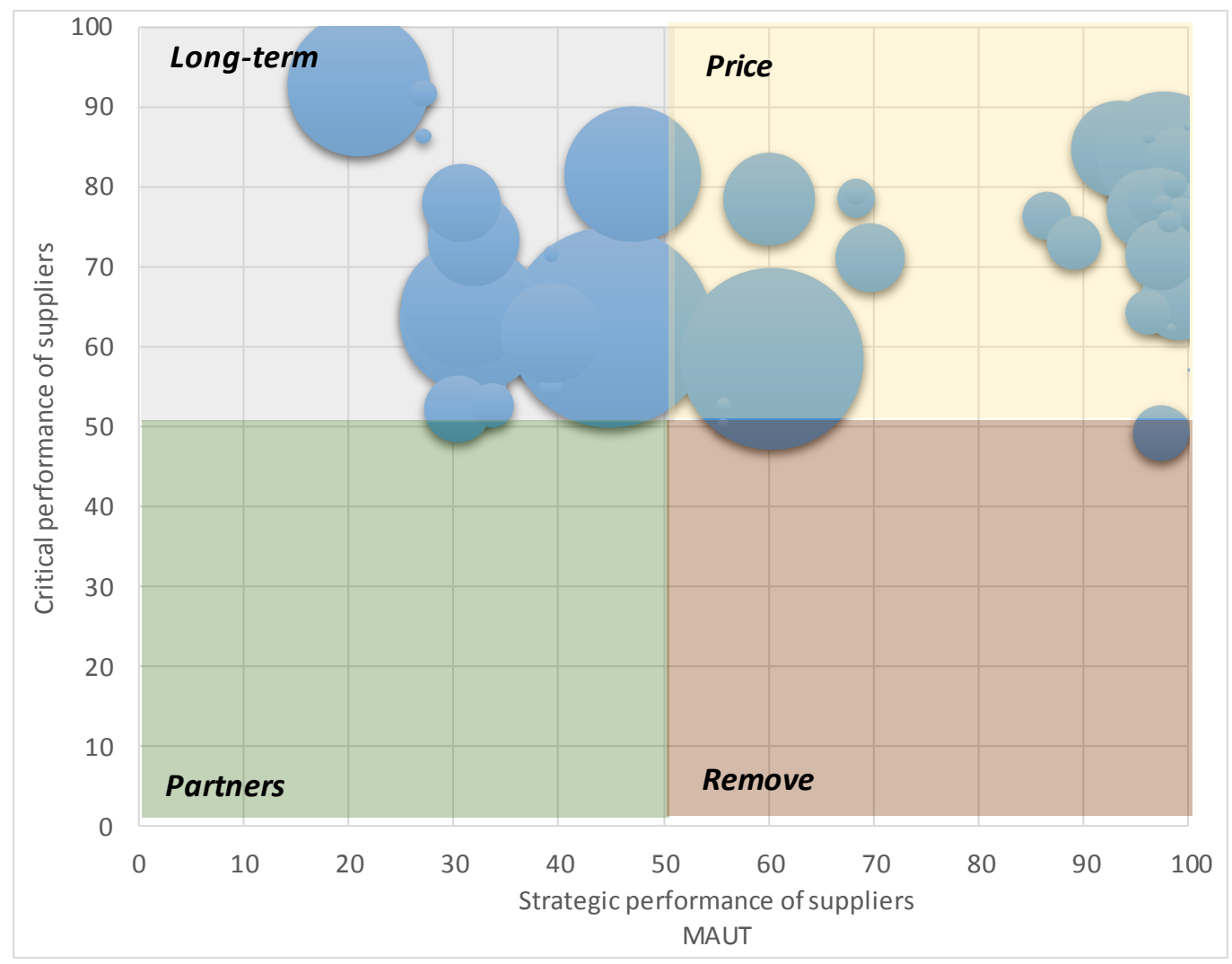

Figure 9. Classification of suppliers according to their critical and strategic performance. MAUT. Bubble size represents the purchase volume of supplier. The higher the score, the better

The differences between scores produced by the both multiple criteria methods, which are compared in this research, are illustrated in figure 10 by showing the strategic scores from MAUT and PROMETHEE obtained by several suppliers. This figure also points out the higher scores assigned to suppliers in MAUT in comparison with PROMETHEE. Nevertheless, differences among suppliers are in the same line in both approaches.
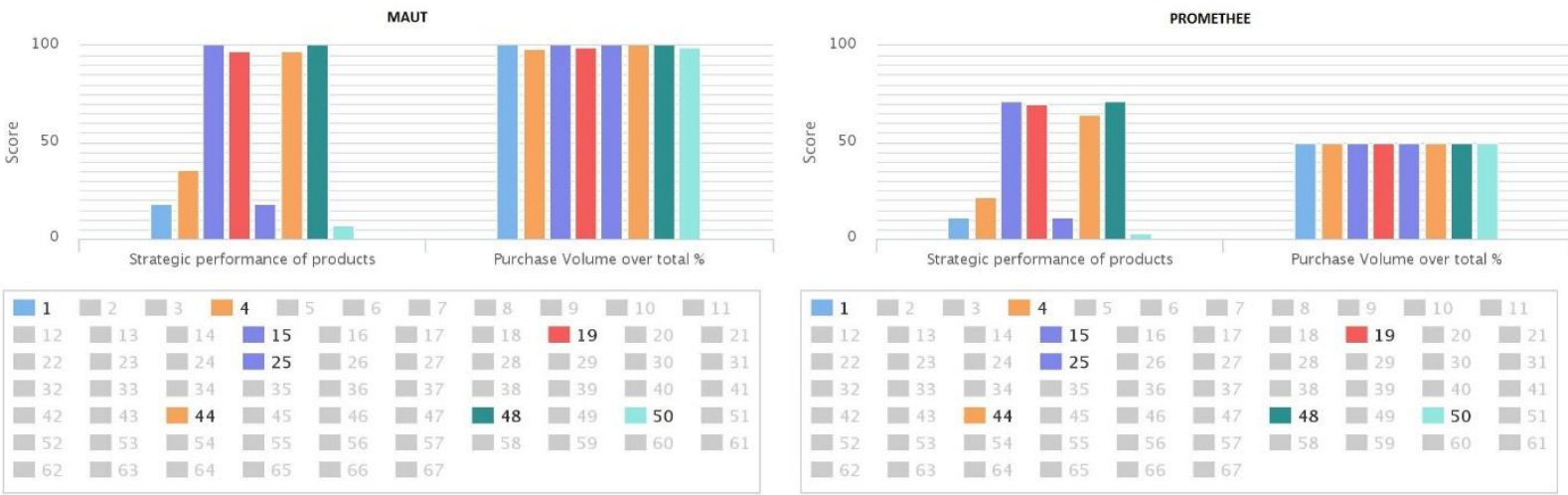

Figure 10. Strategic performance of some suppliers. MAUT and PROMETHEE 


\section{Discussion}

When comparing the system proposed with conceptual and empirical approaches in the literature, some important differences are found. Firstly, Kraljic's method and other portfolio models are based on items (Gelderman \& Van Weele, 2005) instead of suppliers as in this proposal. In an intermediate step the system only allows segmentation related to product dimension, followed by aggregation of the scores for all items provided by a supplier and additional criteria. Then, classification based on suppliers is obtained, which represents a step forward and a novelty with respect to published portfolio models.

Secondly, the system presented is based on two dimensions, critical criteria and strategic criteria. The critical dimension captures the same idea as the supply risk in Kraljic's matrix, although after aggregating all items per provider, in such a way that the points in the matrix are suppliers, not items. The profit impact from Kraljic is now measured as the whole purchase volume from a supplier and is drawn in the matrix as the size of the bubble, as can be seen in figures 7 and 9. Therefore, the strategic dimension which integrates all relevant internal criteria of the products in a first phase and suppliers in the second phase is another novelty of the system proposed. This strategic dimension could be framed in the conceptual model from Olsen and Ellram (Rezaei \& Ortt, 2012). Other dimensions have appeared in the literature, such as buyer's specific investments and supplier's specific investments, economic profile and complexity and risk profile, supplier's added value and supply risk, capabilities and willingness of suppliers (Hallikas et al., 2005, Lee \& Drake,2010; Rezaei \& Ortt ,2012).

Thirdly, the published empirical methods for supplier segmentation are based on surveys, interviews and expert judgements, not only for eliciting the criteria and their weights, but also for rating the suppliers directly with 5-point Likert scale, such as in Gelderman \& Van Weele (2003), Hallikas et al. (2005), Lee \& Drake (2010), Rezaei \& Ortt (2013a, 2013b) and Rezaei et al. (2015). Although these procedures are interesting when companies deal with strategic decisions and there is no data availability, the use of databases, which have more appropriate objective and reliable information for systematic evaluations along the time, is more suitable for a decision support system. This is a requirement if the company wants to monitor the performance of suppliers and what our system offers. In addition, these objective data are analysed by two powerful methods for decision making as PROMETHEE and MAUT, in line with the recommendation from Rezaei \& Ortt (2012).

Moreover, the multiple criteria system proposed can be applied to supplier segmentation by using other dimensions, such as capabilities and willingness of suppliers defined by Rezaei \& Ortt (2012), by selecting the relevant variables for a particular company, the most reliable indicators in order to measure them and carry out all the necessary analysis to develop suitable strategies for supply chain management.

The nature of the problem we are dealing with makes the selection of criteria and their indicators to measure them as the first step and a question of preferences. These preferences have to be set up according to the business strategy and take into account the data availability. Then, the company can elicit the importance of these criteria, usually through their weights in MCDM approaches. There is a wide number of methodologies to do this, from direct assignment to more elaborate ones. This paper proposes AHP, which permits checking the consistency of the individual preferences and also aggregating them with good properties. In particular, we propose this method as a group decision making tool by using the geometric mean to elicit the weights from a group of people as the group decision is always consistent if the individual judgements are consistent (Xu, 2000; Ishizaka \& Labib, 2011). 
As the number of pairwise comparisons increases a lot with the number of criteria in AHP, other approaches have been proposed in order to reduce the time required by managers. This is the case of BWM method developed by Rezaei (2015), which could be included in the system. Finally, application of AHP to elicit the weights of criteria to be used in PROMETHEE and MAUT can be criticised due to the different meaning of weights in both methods, at least theoretically. Nevertheless, this procedure represents an approximate way to model the preferences in practice.

In general, PROMETHEE and MAUT are alternative methods for supplier evaluation which can be used to solve some of the problems related to supply chain management. Nevertheless, as shown in figure 1, MAUT is the appropriate method to qualify suppliers because this process depends only on own features of the supplier, who should be accredited to include in the panel of approved suppliers. After testing that a supplier has all requirements which are established by the company in order to provide a product, the supplier will be qualified for that product. Then the company can compare the approved suppliers with others, either with MAUT or PROMETHEE. Both methods allow ranking suppliers according to their critical and strategic scores in order to select the best or to classify them highlighting the more interesting relationship for purchasing management.

On the one hand, the critical and strategic scores obtained by MAUT depend on the weights of criteria and each supplier's own performance taking into account the utility functions. The preferences of decision makers in PROMETHEE are also considered in the weights of criteria, as well as in the preference functions. While the utility function in MAUT takes into account the value of a criterion for a specific supplier, the preference function in PROMETHEE captures the differences between the values of a criterion of two suppliers who are compared pairwise. This is an essential difference between MAUT and PROMETHEE, as shown in the figures 6 and 8. The comparison of both graphs highlights the compensatory character of MAUT and the highest discriminant power among suppliers by applying PROMETHEE, which is an outranking method and therefore a non-compensatory approach.

The additive model of MAUT is also pointed out in the graphs obtained when representing critical and strategic scores in the axes, and purchase volume in the size of the bubbles for all suppliers. When comparing figures 7 and 9, the suppliers seem to be less critical with MAUT than with PROMETHEE. To clarify the divergence between both methods only several suppliers are represented in figure 10. In fact, MAUT obtains the score by adding the values for the criteria, while PROMETHEE is based on the difference of the criteria values from the pairwise comparison, so a supplier will never have a score of 100 , except when a supplier is extremely better for all criteria which is really difficult in practice. In addition, figure 10 shows that the scores obtained from PROMETHEE are in line with those from MAUT, although the values are higher for the latter case.

PROMETHEE can present the rank reversal problem (the ranking can change when adding new suppliers), which does not appear in MAUT. This problem can have relevance in practice if the performance of suppliers is very similar and the objective is to choose, for example, a few of them from a small group. Nevertheless, no problem exists when monitoring and controlling suppliers to classify them according to their critical and strategic scores.

The proposed system does not permit obtaining the best suppliers and the optimal allocation of products to suppliers simultaneously. This is only possible by applying linear and integer programming, such as in Ekici (2013). On the contrary, these approaches can only optimize one 
objective. This is a drawback in a context of multiple criteria decision making that appears in the majority of real problems related to supply chain management.

Goal programming permits considering several criteria as goals and for this reason it is suitable for more contexts (Wang et al. 2004 applied goal programming and AHP). Multiobjective programming is a less operational approach when there are many criteria, products and suppliers, as can be seen in Amid et al. (2011) who developed a model with one product and three criteria (price, quality and service). It can be said that mathematical programming and our approach based on hybrid multiple criteria method are complementary. For example, it may be interesting to develop mathematical programming models for very critical and strategic products, as well as for strategic suppliers.

Another strength of the system is the flexible way to integrate all relevant quantitative and qualitative criteria from a group decision making perspective. Determining the criteria in order to measure the supplier performance should be based on a specific business strategy (Huang \& Keskar, 2007; Chen, 2011). The most used criteria for supplier selection have been cost, quality and delivery performance. Others, such as financial strength, past experience, claims, distance, safety and risk factors, can be found in the literature. In general the previous studies only consider criteria from suppliers, instead of criteria for products and suppliers. In Bottani \& Rizzi (2008) different criteria of suppliers and products have been included in order to select both suppliers and purchased items for a new receiving process to lead-time reduction by using AHP, cluster analysis and fuzzy logic. DEA approach classifies the criteria of suppliers in output and input in order to group them as efficient or inefficient.

In this research some criteria used in the literature as well as new ones have been considered. Although safety and environmental regulations, delivery time, purchase volume and delays have appeared in other studies, this proposal adds new criteria, which have demonstrated great power to discriminate among suppliers, in order to inform the best relationships to improve supply chain management. These are some strategic criteria of products (contact with the final product, stopping the production of the factory, affect the image of the company), critical performance of products, strategic performance of products and several risk factors from suppliers (commercial, supplier country and supplier billing). Our approach is focused on critical and strategic dimensions, which offer greater power to classify suppliers in contrast to DEA, which is focused mainly on selection taking into account efficient and inefficient performance of providers.

PROMETHEE has been mainly applied to environmental, energy and water management, business and financial management, logistics and manufacturing among other areas (Behzadian et al., 2010). Nevertheless, it has hardly been used to evaluate and select suppliers. Dulmin and Mininno (2003) and Chen et al. (2011) applied this method to supplier selection. Araz \& Ozkarahan (2007) came up with a supplier evaluation method based on PROMETHEE for the product development process, where they classify suppliers in the following groups: perfect, good, moderate and bad. Chen et al. (2011) applied PROMETHEE to an information system for outsourcing under fuzzy environments. As explained, the purpose of the system proposed is different from these applications, which means supplier segmentation in order to inform the best relationships and the suitable strategies of the company. Thus, our proposal uses PROMETHEE in a novel way to reach this goal in a two phase procedure focused on products firstly and on suppliers secondly, and same comments can be applied to MAUT. 


\section{Conclusions}

The evolution of conceptual models for supply chain management has supported the increasing strategic importance in companies and encouraged staff professionalism. Nevertheless, in the literature there is a smaller number of empirical models, probably due to difficulties to measure the relevant criteria in practice. The majority of the huge amount of published articles only focuses on the selection phase. Thus, there are not any decision support systems that contribute significantly to decision making in all phases of the procedure of the modern supplier management and this is the main contribution of the system proposed in this paper.

The proposal represents an integrated novel approach to deal with qualifying suppliers per each product, followed by selecting the best providers and monitoring suppliers by systematic evaluation in order to develop the more appropriate relationship with suppliers. To integrate all these phases in a unified system three MCDM methods have been necessary: AHP, PROMETHEE and MAUT. For companies it is interesting to have a unique tool to support all decision making problems of supplier management.

The greater contribution of our system is related to supplier segmentation for several reasons. We have proposed new strategic and critical dimensions to classify suppliers by using historical and reliable data needed in a system which will be able to support decision making at operative, tactical and strategic level. Due to multiple criteria nature of this problem, subjective preferences of the company have been taken into account through AHP, which is also suitable for aggregating preferences from a group of people. The novelty consists of the analysis of objective data carried out by using two powerful multiple criteria methods, PROMETHEE and MAUT, which have been tested and compared, in a two phase procedure, which involve products in the first one and suppliers in the second.

This system has been validated in a real implementation in a big manufacturing company, which works for several sectors such as food, pharmaceuticals and chemicals. Experimental results have shown the flexibility, robustness and applicability of PROMETHEE as an outranking method for supplier segmentation and finally to inform the best strategies in supplier management. Not only does it allow the aggregation of quantitative and qualitative indicators of relevant criteria, but it also takes into account the preferences of the company when comparing pairwise suppliers, based on objective indicators, in addition to the weights of criteria as common in many MCDM methods. MAUT is also flexible and applicable for supplier segmentation, but as compensatory method it has less discriminant power among suppliers than PROMETHEE. On the contrary, MAUT is easier to understand and then to apply by the purchasing department staff. A system which includes both methods provides more advanced analytical capabilities.

Both methods, PROMETHEE and MAUT, allow classifying suppliers according to critical and strategic performance in a two dimension matrix periodically, which can be divided in four quadrants. The suppliers which are very critical and strategic for the company should be partners, while long term contracts are more suitable for strategic suppliers, which are not critical. When a supplier is less critical and strategic, the better relationship has to be guided by market price. Finally, when suppliers are very critical, but little strategic, the company should remove them from the portfolio or move onto another quadrant in case they improve their performance. These recommendations have to be based on the analysis of systematic and continuing evaluations of the suppliers, such as monthly assessments, quarterly or annually, in order to test and verify the evolution of supplier performance. 
This system has shown a great impact as it represents the first supplier segmentation proposal applied to industry, in which decision making integrates historical data and expert knowledge, not only takes into account opinions, judgements and/or direct rating from managers. Thus, this approach provides a robust support system to inform operative, tactical and strategic decisions, which is very relevant when applying an advanced management in practice.

Finally, in future research it is interesting to develop empirical studies applying this system with other dimensions and criteria proposed by other authors, which would be more suitable for the company according to the economic sector and their general goals. In particular, developing decision support systems which integrate a sustainability dimension of suppliers can represent a competitive advantage for many companies, in line with Seuring (2013) who highlighted the interest of assessing green supply chains empirically by using multiple criteria approach.

\section{Acknowledgments}

This research has been partially developed with the support of the Ministry of Economy and Competitiveness (Ref. ECO2011-27369) and Ministry of Education (Marina Segura, scholarship of Training Plan of University Teaching). The authors thank the company for providing real problems and data and the personnel of the purchasing department for helping us to understand the complex nature of supplier management and the great interest in automatizing and informing decision making. We also thank the editor and reviewers for their suggestions to improve the paper.

\section{References}

Amid, A., Ghodsypour, S.H., \& O'Brien, C. (2011). A weighted max-min model for fuzzy multi-objective supplier selection in a supply chain. International Journal of Production Economics, 131, 139-144.

Araz, C., \& Ozkarahan, I. (2007). Supplier evaluation and management system for strategic sourcing based on a new multicriteria sorting procedure. International Journal of Production Economics, 106, 585-606.

Behzadian, M., Kazemzadeh, R.B., Albadvi, A., \& Aghdasi, M. (2010). PROMETHEE: A comprehensive literature review on methodologies and applications. European Journal of Operational Research, 200, 198-215.

Belton, V., \& Stewart, T. (2003). Multiple criteria decision analysis: an integrated approach. Kluwer Academic Publishers, Dordrecht, Netherlands.

Bottani, E., \& Rizzi, A. (2008). An adapted multi-criteria approach to suppliers and products selection - an application oriented to lead-time reduction. International Journal of Production Economics, 111, 763-781.

Brans, J.P., \& Mareschal, B. (2005). PROMETHEE Methods, chapter 5 en Multiple Criteria Decision Analysis (pp.163-195). State of the Art Surveys, in Figuera, J., Greco, S., Ehrgott, M., Springer.

Chai, J.Y., Liu, J.N., \& Ngai, E. (2013). Application of decision-making techniques in supplier selection: A systematic review of literature. Expert Systems with Applications, 40, 3872-3885. 
Chang, L., Ouzrout, Y., Nongaillard, A., Bouras, A., \& Jiliu, Z. (2014). Multi-criteria decision making based on trust and reputation in supply chain. International Journal of Production Economics, 147, 362-372.

Chen, Y.J., (2011). Structured methodology for supplier selection and evaluation in a supply chain. Information Sciences 181, 1651-1670.

Chen, Y.H., Wang, T.C., Wu, C.Y. (2011). Strategic decisions using the fuzzy PROMETHEE for IS outsourcing. Expert Systems with Applications 38, 13216-13222

Day, M., Magnan, G.M., Moeller, M.M (2010). Evaluating the bases of supplier segmentation: A review and taxonomy. Industrial Marketing Management, 39, 625-639.

Demirtas, E.A., \& Üstün, O. (2008). An integrated multiobjective decision making process for supplier selection and order allocation. Omega, 36, 76-90.

D-Sight CDM. (2016). Available from: http://www.d-sight.com/solutions/d-sight-cdm.

Dulmin, R., \& Mininno, V. (2003). Supplier selection using a multi-criteria decision aid method. Journal of Purchasing \& Supply Management, 9,177-187.

Dweiri, F., Kumar, S., Khan, S.H., \& Jain, V. (2016). Designing an integrated AHP based decision support system for supplier selection in automotive industry. Expert Systems With Applications, 62, 273-283.

Ekici, A. (2013). An improved model for supplier selection under capacity constraint and multiple criteria. International Journal of Production Economics, 141, 574-581.

Gelderman, C.J. , \& Van Weele, A. J. (2003). Handling measurement issues and strategic directions in Kraljic's purchasing portfolio model. Journal of Purchasing \& Supply Management, 9,207-216.

Gelderman, C.J. , \& Van Weele, A. J. (2005). Purchasing Portfolio Models: A Critique and Update, 41 (3), 19-28.

Hallikas, J., Puumalainen, K., Vesterinen,T., \& Virolainen, V. (2005). Risk-based classification of supplier relationships. Journal of Purchasing \& Supply Management, 11, 72-82.

Ho, W., Xu, X., \& Dey, P.K. (2010). Multi-criteria decision making approaches for supplier evaluation and selection: A literature review. European Journal of Operational Research, 202, $16-24$.

Huang, S.H., \& Keskar, H. (2007). Comprehensive and configurable metrics for supplier selection. International Journal of Production Economics, 105, 510-523.

Ishizaka, A. \& Labib, A. (2011). Review of the main developments in the analytic hierarchy process. Expert Systems with Applications, 38, 14336-14345.

Kar, A.K. (2014). Revisiting the supplier selection problem: An integrated approach for group decision support. Expert Systems with Applications, 41, 2762-2771.

Kraljic, P., 1983. Purchasing must become supply management. Harvard Business Review, 61 (5), 109-117.

Lee, D.M. \& Drake, P.R. (2010). A portfolio model for component purchasing strategy and the case study of two South Korean elevator manufacturers. International Journal of Production Research, 48 (22), 6651-6682.

Lin, R. (2012). An integrated model for supplier selection under a fuzzy situation. International Journal of Production Economics, 138, 55-61. 
Rezaei, J. (2015). Best-worst multi-criteria decision-making method. Omega, 3, 49-57.

Rezaei, J., \& Ortt, R. (2012). A multi-variable approach to supplier segmentation. International Journal of Production Research, 50, 4593-4611.

Rezaei, J., \& Ortt, R. (2013a). Multi-criteria supplier segmentation using a fuzzy preference relations based AHP. European Journal of Operational Research, 225, 75-84.

Rezaei, J., \& Ortt, R. (2013b). Supplier segmentation using fuzzy logic. Industrial Marketing Management 42, 507-517.

Rezaei, J., Wang, J., \& Tavasszy, L. (2015). Linking supplier development to supplier segmentation using Best Worst Method. Expert Systems with Applications 42, 9152-9164.

Saaty, T.L., \& Peniwati, K. (2008). Group decision making: drawing out and reconciling differences. RWS Publications.

Saaty, T.L., \& Vargas, L.G. (2001). Models, methods, concepts \& applications of the analytic hierarchy process. Kluwer Academic Publishers.

Sen, C.G., Baraçlı, H., Sen, S., \& Baslıgil, H. (2009). An integrated decision support system dealing with qualitative and quantitative objectives for enterprise software selection. Expert Systems with Applications, 36, 5272-5283.

Seuring, S. (2013). A review of modeling approaches for sustainable supply chain management. Decision Support Systems, 54, 1513-1520.

Wang, G., Huang, S.H., \& Dismukes, J.P. (2004). Product-driven supply chain selection using integrated multi-criteria decision-making methodology. International Journal of Production Economics, 91, 1-15.

$\mathrm{Xu}, \mathrm{Z}$. (2000). On consistency of the weighted geometric mean complex judgement matrix in AHP. European Journal of Operational Research, 126, 683-687.

Zeydan, M., Çolpan, C., \& Çobanoglu, C. (2011). A combined methodology for supplier selection and performance evaluation. Expert Systems with Applications 38, 2741-2751. 